Article

\title{
Online Academic Networks as Knowledge Brokers: The Mediating Role of Organizational Support
}

\author{
Elena-Mădălina Vătămănescu ${ }^{1, *}$ (D), Andreia Gabriela Andrei ${ }^{2}$ (D), Patrizia Gazzola 3 (iD) \\ and Gandolfo Dominici ${ }^{4}$ \\ 1 Faculty of Management, National University of Political Studies and Public Administration, \\ Bucharest 012104, Romania \\ 2 Interdisciplinary Research Department of Social Sciences and Humanities, Alexandru Ioan Cuza University, \\ Iasi 700506, Romania; andrei.andreia@gmail.com \\ 3 Department of Economics, University of Insubria, 21100 Varese, Italy; patrizia.gazzola@uninsubria.it \\ 4 Department of Economics, Business and Statistical Sciences (DSEAS), University of Palermo, 90128 Palermo, \\ Italy; gandolfo.dominici@unipa.it \\ * Correspondence: madalina.vatamanescu@facultateademanagement.ro; Tel.: +4-07-4811-9900
}

Received: 21 March 2018; Accepted: 10 April 2018; Published: 14 April 2018

check for updates

\begin{abstract}
Placing online academic networks in the framework of social, cultural and institutional "deterritorialization," the current paper aims at investigating the functionality of these new forms of transnational and trans-organizational aggregations as knowledge brokers. The emphasis is laid on the influence of human collective intelligence and consistent knowledge flows on research innovation, considering the role of organizational support within higher education systems. In this respect, the research relied on a questionnaire-based survey with 140 academics from European emerging countries, the data collected being processed via a partial least squares structural equation modelling technique. Evidence was brought that, as knowledge brokers, online academic networks are systems aimed to support the access to human collective intelligence and consistent knowledge flows which exert a positive influence on research innovation, both directly and indirectly, by means of formal and informal organizational support. As facilitators of collaborative environments for individuals with specialized knowledge, competence, expertise and experience, online academic networks have set themselves up as an agora for academics worldwide and as an outlet for their acumen and literacy.
\end{abstract}

Keywords: knowledge brokers; brokerage; online academic networks; organizational support; deterritorialization

\section{Introduction}

The patterns of globalization — in the sense of "deterritorialization" — as posited by Tomlinson [1,2], imply that classical cultural-spatial, institutional and political-economic borders have been relativized nowadays by cross-border interdependencies and interconnections. Deterritorialization underpins the reality of "disembedding" social relationships from national-centric grounds, by giving way to transnational forms of association among individuals, organizations, networks and societies. In line with the globalizing attributes of modernity, new types of social aggregations emerge with a high potential to reframe the web of life and its subsequent processes.

The deterritorialization phenomena are also objectivized via the transition to the knowledge economy [3-5] which has entailed new challenges and imperatives for higher education systems: the goal to innovate and to be increasingly competitive has pushed higher institutions out of their domestic habitat and favoured knowledge transfer and sharing across organizations, countries or regions. By bridging the divide, universities, research centres and institutes have been progressively 
put into contact and external relations have been encouraged in both institutionalized and informal ways [5].

As sheer institutionalized relationships often lack flexibility and rapid adjustments, more dynamic social aggregations have sprung to support trans-organizational knowledge renewal by means of inter-organizational learning, good practices and access to the work of reputed scholars in different fields [5]. Built on the foundations of the digital era and of the network society [6-12] with a view to support the transformation of adaptive to generative learning [13-15], online academic networks have set the scene for new patterns of knowledge access, exchange, transfer, diffusion, discovery and so forth. Progressively, under the aegis of the Internet which "facilitates circulation of knowledge" and reframes collaboration among peers [16], online academic networks emerged as knowledge brokers for various categories of stakeholders, putting up a stronger rationale in terms of knowledge sharing.

Building on this logic and given the fact that knowledge brokerage is yet to be thoroughly researched in the academia field, the current paper intends to discuss the role of online academic networks as knowledge brokers able to generate significant value by bridging scholars from developed economies with their counterparts from emerging economies, by allowing and potentiating the access to an agora of human collective intelligence, to cutting-edge studies, projects, events and so forth, to educational and research centres with less available resources. By assuming both interconnector and gatekeeping roles, as portrayed by Belso-Martinez et al. [17] within the context of clusters and by means of sharing knowledge among the network members (be they individuals or organizations), the online academic networks-founded on intensive usage of the information and communication technology-succeed in keeping people connected and stimulating cohesive network structures.

In this front, the research challenge is twofold.

On the one hand, its focus is to investigate the relationship between the knowledge brokerage function of online academic networks in terms of knowledge transfer from well-reputed scholars and organizations to their less-resourceful counterparts (including here lower research budgets, poorer research infrastructure and logistics, less experience and expertise of research teams in specialized fields, etc.).

On the other hand, emphasis is laid on the mediating role of the organizational support in knowledge brokerage performance. Here, the research questions regard whether less-resourceful organizations encourage, both formally and informally, that their members access and capitalize the resources made available by knowledge brokers and to what extent is innovation influenced by such actions. In this point, the research endeavour is intended to provide a suitable answer to the extant knowledge gap revealed by Hammami et al. [18] who underscore that the role of organizational support is still under-researched although credited as relevant within the knowledge brokerage framework.

Pursuant to these argumentative directions, the paper was structured in five main sections, as follows: firstly, the literature review was presented; secondly the research hypotheses and model were developed; thirdly, the material and method were accounted for: fourthly, the results of the investigation were reported and, finally, the findings were discussed and conclusions were drawn.

\section{Literature Review}

Starting from the state-of-the-art, online academic networks have achieved new functions and roles, among which their capacity as knowledge brokers has steadily come forth. Knowledge brokers refer to the individuals or organizations that yield benefits from transferring ideas from where they are well-known and developed to where they engender innovative opportunities [19,20]. Placed in the framework of knowledge management, knowledge brokerage (brokering) has come forth as a topical research interest, with a special focus on the private sector. Nevertheless, addressed as a comprehensive pathway to spread knowledge within and across organizations and as an innovation-facilitating mechanism, knowledge brokerage has incrementally surpassed the boundaries of the business environment, immersing into the public sector. At this level, three different settings have been advanced on purpose to capture its objectivation functions beyond the private sector, that is the 
knowledge system framework (i.e., referring to the facilitator role of knowledge brokerage in the generation, diffusion and capitalization of knowledge), the transactional framework (i.e., portraying knowledge brokers as linkage agents who ensure substantive bonds between knowledge creators and users) and the social change framework (i.e., approaching knowledge brokers as enhancers of knowledge conducive to positive social outcomes or to capacity building) [21].

Either seen as knowledge transfer facilitators or as innovators, knowledge brokers are acknowledged for their capacity to translate knowledge and to harmonize social differences, to act as individual or organizational entities which leverage the potential of specialized networks to access, combine, transform knowledge in new useful ways [18-20]. Knowledge brokers are constantly oriented to bridge the gaps between resources and knowledge by establishing systemic connections which facilitate interactions and relationships among different parties that otherwise would not be connected and/or able to communicate [22]. In this front, Malinovskyte, Mothe and Rüling [21] deem that the ever more fragmented societies and economies provide steadily increasing opportunities for knowledge brokerage as well as an increasing need for empirically grounded knowledge enabling the design of effective brokerage roles in the future.

Networks play an important role in the innovative knowledge brokerage because knowledge brokers rely on their social networks to select partners that could be useful and interested in the new knowledge [23,24], analysing the external environment in search for potential opportunities and how to address them. Here, online academic networks emerge as knowledge brokers, especially in their capacity as mediators, bridging structural holes $[4,18,25,26]$. Structural holes refer to the absence of a link between two contacts that are both linked to a third actor [27], resulting in a situation in which 'people on either side of a structural hole circulate in different flows information' [28] (p. 209).

The existence of structural holes constitutes opportunities for third parties to mediate the flow of information among disconnected actors $[29,30]$.

Hargadon [31] builds upon the notion of structural holes and further expands the fragmented environments within the scope of knowledge brokerage. Fragmented environments are marked by the phenomenon of 'small worlds,' allowing knowledge brokers to operate in a context in which every domain is characterized by habitualized actions, interactions and beliefs resulting in distinct 'institutional logics' [32]. On purpose to overcome the boundaries of these disconnected entities, online academic networks in their capacity as knowledge brokers sustain the emergence and development of significant value within and across worldwide organizations [5,33], the advances in knowledge management encompassing sharing knowledge among network members at a global level [34,35].

The configuration of the digital era-as objectivized via intensive use of information and communication technologies (ICTs) and (hyper)connectivity [36,37]—stimulates the emergence of new forms of collective intelligence and types of collaboration throughout the network [38,39]. In this regard, different studies $[40,41]$ have posited that collective intelligence fostered by groups working both face-to-face and virtually could lead to a higher level of knowledge production and to better performance and thus innovation. Online networks have dramatically increased the speed of knowledge sharing and exchanging, posing a noteworthy influence on the innovation capacity of the collective intelligence [5,42].

This approach has progressively pushed knowledge management conceptualizations towards academia, as supported by a myriad of studies [43-47] and has brought forward the value of non-tangible assets comprising capacities, processes, talents and skills, networks of collaborators and contacts [48-50]. Most of today's networks surpass the borders of the organization, developing inter-organizational and trans-organizational relationships within a collaborative macro-environment [51].

In this context, online academic networks as knowledge brokers ensure stronger collaboration tools, setting the scene for an agora for the reification of human collective intelligence. Networks arise as social systems with the global objective of knowledge sharing among academics, researchers, institutions and communities who accepted generative learning as a common value. By attributing a systemic functionality to networks in line with the scope of knowledge brokerage, the collective 
human intelligence becomes the driving force of consistent flows of innovation and of competitiveness achievements [5,52,53].

Laying emphasis on the relational processes among worldwide researchers and academics, the research of Vătămănescu et al. [5] discussed the role of online academic networks in knowledge sharing. A new termed was introduced and coined, namely the network-based intellectual capital, defined "as an intricate configuration and consistent interaction among people, knowledge, information, expertise, competences, know-how within complex and dynamic online social networks." (p. 596). In this vein, the systemic logic of trans-organizational flows relied on a twofold goal: the individual's purposeful actions to gain access to the network's resources for self-improvement and the organizational purposeful strategies to harness new knowledge wells for capacity building and innovation.

Therefore, individuals are put in motion and collaborate due to a dyadic rationale. Moreover, according to the rationale of the knowledge-based society, the substantive relationships among individuals aim to support knowledge transfer and sharing, thus turning themselves into key drivers of innovation [54-56]. This is also underlined by Valkokari et al. [57] when discussing the importance of collaboration processes in the framework of networked innovation. Via collaboration on various research projects, via sharing experience and expertise among the network actors, new sources of knowledge emerge and innovative outcomes are generated [58].

At this level, organizational support is crucial in both shaping and legitimizing individuals' understandings and appropriate actions towards knowledge brokerage [31] (p. 53). Organizational support is credited with a high influence in capitalizing knowledge brokerage with a view to innovation [18,19]. For example, as a conclusion of their study, Leon and Vătămănescu [59] (p. 460) urge that "in order for the strategic approach to be successful, it is necessary for the decision makers to define the objective (what type of knowledge they want to share and why), to define the message [...] then to evaluate the effects." The authors presume that the organization's institutionalized systems for knowledge acquisition are of the essence in order to engender innovation.

This perspective was previously assumed by other studies [60-62] which addressed the need for clear institutional policies and practices for knowledge generation, diffusion, accumulation and embodiment and the development of a specific organizational behaviour and culture in this respect. Therefore, transforming knowledge-based processes in pivotal innovation factors often require explicit organizational strategies and capacities to fuel and channel knowledge among and across specialized networks [52,63-65].

\section{Research Hypotheses and Model}

Based on the previous theoretical developments, five main hypotheses were formulated, as follows:

H1: As knowledge brokers, online academic networks support the access to human collective intelligence which exerts a positive influence on research innovation.

H2: As knowledge brokers, online academic networks support consistent knowledge flows which exert a positive influence on research innovation.

H3: The access to human collective intelligence within online academic networks exerts a positive influence on organizational support, be it formal (H3a) or informal (H3b).

H4: The consistent knowledge flows within online academic networks exert a positive influence on organizational support, be it formal (H4a) or informal (H4b).

H5: Organizational support exerts a positive influence on research innovation, be it formal (H5a) or informal (H5b).

By corroborating the inferred relationships among the constructs, we developed research model illustrated below (Figure 1). 


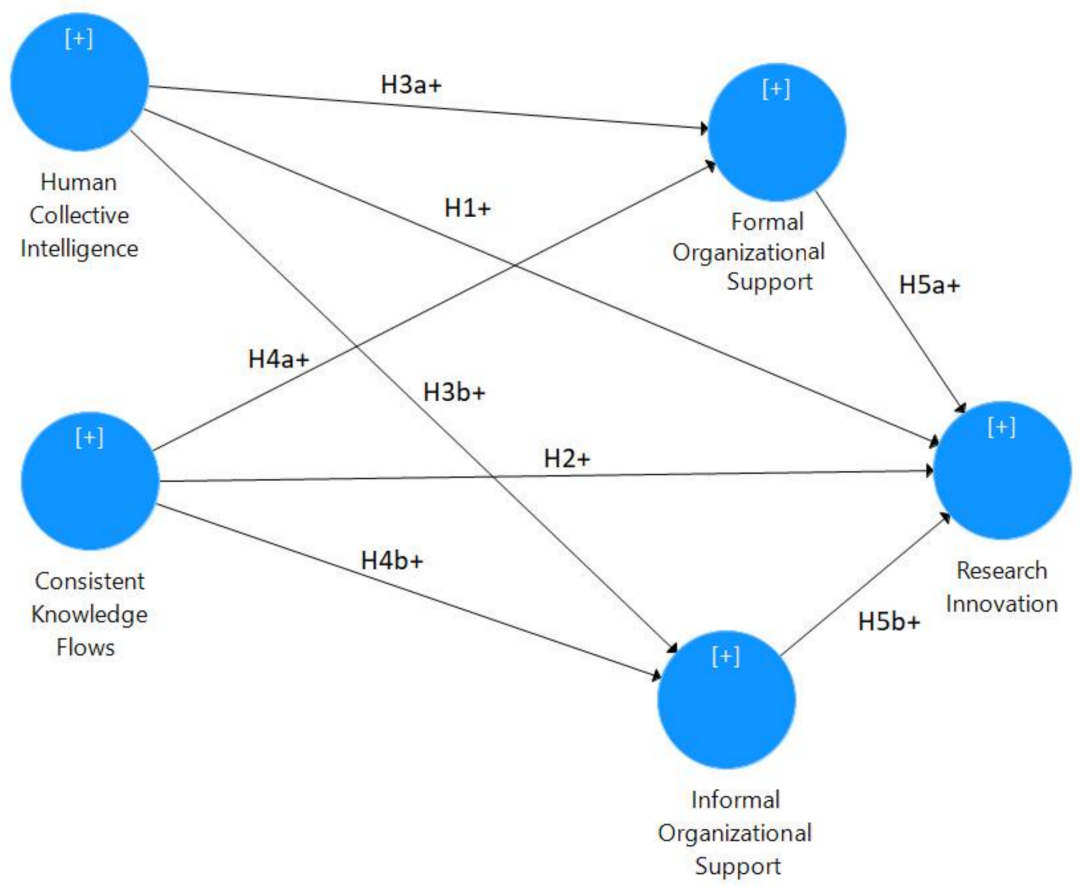

Figure 1. Research model with hypotheses.

\section{Materials and Methods}

\subsection{Data Collection and Sample}

A total of 140 academics from European emerging countries participated to the current study. Subjects were invited to contribute to a questionnaire-based survey on the configuration and functions of online academic networks during two international academic events held in September and November 2017, in Romania. Participants were asked to fill out a self-administered questionnaire comprising 38 closed-ended questions and socio-demographic items. At this level, the great majority of respondents were aged between 36 and 45 years old, had an experience in the field of more than 10 years and joined more than 3 specialized online academic networks in social sciences.

\subsection{Measures}

The research aimed at testing the relationships between five main multi-item constructs in line with the prior theoretical developments, that is: (a) Human Collective Intelligence (referring to the active presence of well-reputed scholars in the online academic networks-6 items); (b) Consistent Knowledge Flows (referring to the communication and interaction flows developed on a regular basis among the members of the online academic networks - 7 items); (c) Formal Organizational Support (referring to the institutional policies and practices for encouraging knowledge processes within online academic networks-3 items); (d) Informal Organizational Support (referring to the non-institutionalized practices for encouraging knowledge processes within online academic networks - 2 items); (e) Research Innovation (referring to the new research deliverables in terms of articles published in high-ranked journals, international research projects, etc.-6 items).

All the constructs were designed as reflective and were measured using a 5-point Likert scale ranging from 1 (to a very small extent) to 5 (to a very great extent). In this vein, the constructs consisted of previously developed indicators (as described in the introductive section), both exogenous and endogenous variables depending on self-reported measures. 


\section{Results}

\subsection{Measurement Model Assessment}

The Partial Least Squares Structural Equation Modelling (PLS-SEM) norms [66,67] and SmartPLS software [68] were employed to assess the model fit (GoF), the measurement model and the structural model. The model fit $(\mathrm{GoF})$ was indicated by means of the value of the standardized root mean square residual $(S R M R=0.074)$, which was found to be lower than 0.08 threshold introduced by Hu and Bentler [69]. Therefore, the measurement model was further analysed and the results were reported in the tables below (Tables 1-3).

Table 1. Construct Reliability and Validity.

\begin{tabular}{|c|c|c|c|c|}
\hline Constructs & $\alpha$ & rho_A & CR & AVE \\
\hline $\begin{array}{c}\text { Consistent Knowledge Flows } \\
\text { (7 items: CHF2; CHF3; CHF4; CHF5; CHF6; CHF7; CHF9) }\end{array}$ & 0.924 & 0.928 & 0.939 & 0.686 \\
\hline $\begin{array}{l}\text { Formal Organizational Support } \\
\quad(3 \text { items: OS1; OS3; OS6) }\end{array}$ & 0.890 & 0.924 & 0.931 & 0.818 \\
\hline $\begin{array}{c}\text { Human Collective Intelligence } \\
\text { (6 items: HCI3; HCI5; HCI6; HCI8; HCI9; HCI10) }\end{array}$ & 0.897 & 0.903 & 0.920 & 0.659 \\
\hline $\begin{array}{l}\text { Informal Organizational Support } \\
\quad(2 \text { items: OS7i; OS8i) }\end{array}$ & 0.838 & 0.838 & 0.925 & 0.860 \\
\hline $\begin{array}{c}\text { Research Innovation } \\
\text { (6 items: CER4; CER5; CER6; CER8; CER9; CER1) }\end{array}$ & 0.892 & 0.894 & 0.918 & 0.651 \\
\hline
\end{tabular}

Abbreviations in the table: $\alpha$ (Cronbach's $\alpha$ coefficient), rho_A (rho_A coefficient, a consistent reliability measure of PLS construct scores), CR (Composite Reliability), AVE (Average Variance Extracted).

Table 2. Fornell-Larcker Criterion.

\begin{tabular}{|c|c|c|c|c|c|}
\hline & $\begin{array}{c}\text { Consistent } \\
\text { Knowledge Flows } \\
\end{array}$ & $\begin{array}{c}\text { Formal Organizational } \\
\text { Support }\end{array}$ & $\begin{array}{c}\text { Human Collective } \\
\text { Intelligence }\end{array}$ & $\begin{array}{c}\text { Informal } \\
\text { Organizational Support }\end{array}$ & $\begin{array}{c}\text { Research } \\
\text { Innovation }\end{array}$ \\
\hline Consistent Knowledge Flows & 0.828 & & & & \\
\hline Formal Organizational Support & 0.405 & 0.905 & & & \\
\hline Informal Organizational Support & 0.606 & 0.474 & 0.626 & 0.928 & \\
\hline Research Innovation & 0.730 & 0.533 & 0.735 & 0.686 & 0.807 \\
\hline
\end{tabular}

Table 3. Heterotrait-Monotrait Ratio (HTMT).

\begin{tabular}{ccccc}
\hline & $\begin{array}{c}\text { Consistent } \\
\text { Knowledge Flows }\end{array}$ & $\begin{array}{c}\text { Formal Organizational } \\
\text { Support }\end{array}$ & $\begin{array}{c}\text { Human Collective } \\
\text { Intelligence }\end{array}$ & $\begin{array}{c}\text { Informal } \\
\text { Organizational Support }\end{array}$ \\
$\begin{array}{c}\text { Research } \\
\text { Innovation }\end{array}$ \\
\hline Consistent Knowledge Flows & & & & \\
Formal Organizational Support & 0.435 & 0.452 & & \\
Human Collective Intelligence & 0.640 & 0.538 & 0.717 & 0.794 \\
Informal Organizational Support & 0.679 & 0.584 & 0.812 & \\
Research Innovation & 0.802 & & & \\
\hline
\end{tabular}

The statistics presented in Table 1 indicate that the five reflective constructs included in the model (Consistent Knowledge Flows; Formal Organizational Support; Human Collective Intelligence; Informal Organizational Support; Research Innovation) meet the reliability and validity criteria (Cronbach's $\alpha>0.7$; rho_A $>0.7$; composite reliability CR $>0.8$; AVE $>0.5$ ) indicated by the specialized literature $[67,70,71]$.

The statistics detailed in Tables 2 and 3 demonstrate that the measurement model meets discriminant validity criteria, the results reported in Table 2 showing that the squared correlations are lower than the diagonal values (AVE values) — as Fornell and Larker [70] highlighted and the results presented in Table 3 showing that the heterotrait-monotrait ratio (HTMT) of correlations are lower than 1 (HTMT values < 0.90 limit, as Henseler et al. [66,72] recommended). 
According to Diamantopoulos and Siguaw [73], the criterion of no multi-collinearity among constructs was also met, as VIF values of the constructs (between 1.355 and 2.033) are lower than the threshold of 3.3 .

\subsection{Structural Model Assessment}

As the measurement model complied with all PLS-SEM requirements [66,67], the structural relationships were analysed using a 5000-samples bootstrap procedure as indicated in Hair et al. [67,74]. The results were illustrated in Figure 2.

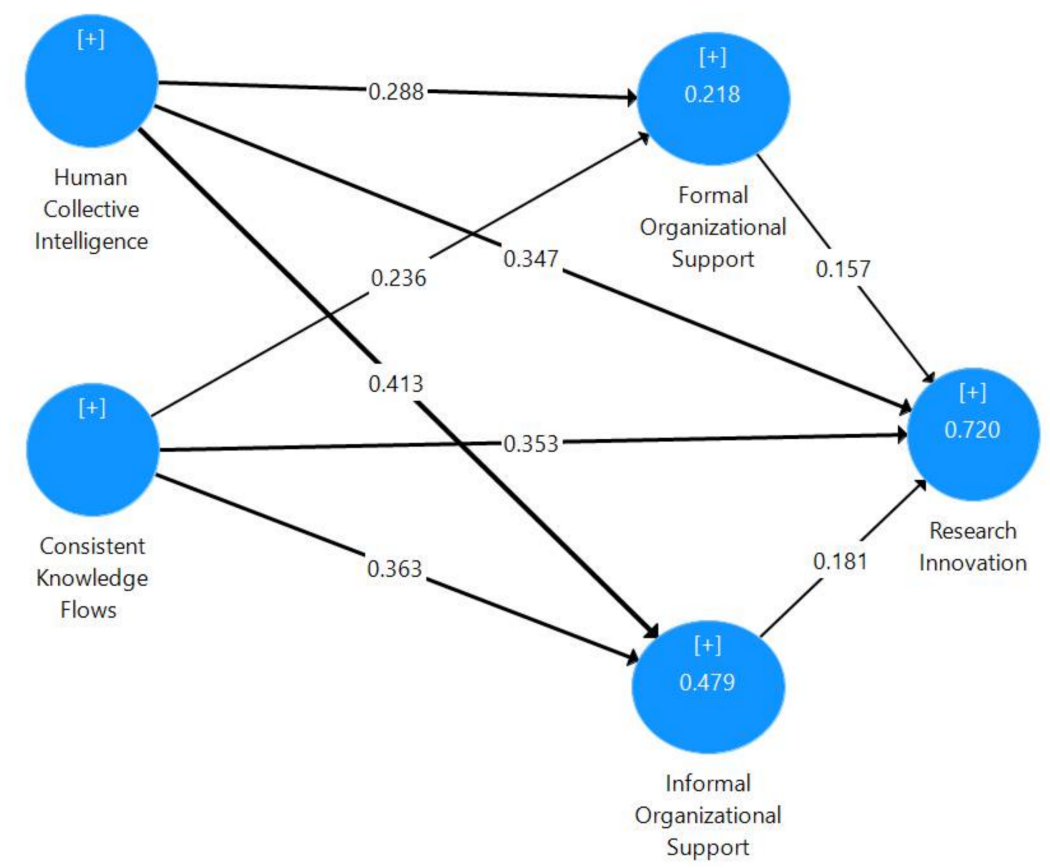

Figure 2. Structural model.

The results of structural relationships assessment indicate that the model explains $72 \%$ of the variance of Research Innovation, respectively $47.9 \%$ of Informal Organizational Support; $21.8 \%$ of Formal Organizational Support (see R square values in Table 4) and each dimension exerts a significant influence on Research Innovation (as shown by the path coefficients and their statistical significance in Table 5).

Table 4. R square.

\begin{tabular}{cc}
\hline & R Square \\
\hline Formal Organizational Support & 0.218 \\
Informal Organizational Support & 0.479 \\
Research Innovation & 0.720 \\
\hline
\end{tabular}

As Figure 2 and Table 5 indicate, the variable Research Innovation is positively and directly influenced by the variables Formal Organizational Support $(\beta=0.157 ; \mathrm{t}=3.131 ; p=0.022 ; \mathrm{H} 5 \mathrm{a}$ is thus supported) and Informal Organizational Support ( $\beta=0.181 ; \mathrm{t}=2.417 ; p=0.02 ; \mathrm{H} 5 \mathrm{~b}$ is thus supported), while each of the exogenous variables Human Collective Intelligence and Consistent Knowledge Flows exert both direct and indirect effects on Research Innovation via Formal Organizational Support and Informal Organizational Support, confirming $\mathrm{H} 1$ and $\mathrm{H} 3$ as follows. 
Table 5. Structural Model Relationships.

\begin{tabular}{|c|c|c|c|c|c|c|c|c|}
\hline Effects & $\beta$ & $\mathbf{M}$ & Stdev & $\mathbf{T}$ & $\mathbf{P}$ & $2.5 \% \mathrm{CI}$ & $97.5 \% \mathrm{CI}$ & Hypothesis \\
\hline $\begin{array}{c}\text { Human Collective Intelligence } \rightarrow \\
\text { Research Innovation (Direct) }\end{array}$ & 0.347 & 0.347 & 0.072 & 4.853 & 0.000 & 0.200 & 0.484 & \multirow{3}{*}{ H1 supported } \\
\hline $\begin{array}{l}\text { Human Collective Intelligence } \rightarrow \\
\text { Formal Organizational Support } \rightarrow \\
\quad \text { Research Innovation (Indirect) }\end{array}$ & 0.045 & 0.045 & 0.021 & 2.196 & 0.028 & 0.012 & 0.091 & \\
\hline $\begin{array}{l}\text { Human Collective Intelligence } \rightarrow \\
\text { Informal Organizational Support } \rightarrow \\
\text { Research Innovation (Indirect) }\end{array}$ & 0.075 & 0.077 & 0.039 & 1.896 & 0.058 & 0.012 & 0.164 & \\
\hline $\begin{array}{l}\text { Consistent Knowledge Flows } \rightarrow \\
\text { Research Innovation (Direct) }\end{array}$ & 0.353 & 0.355 & 0.070 & 5.030 & 0.000 & 0.215 & 0.487 & H2 supported \\
\hline $\begin{array}{l}\text { Consistent Knowledge Flows } \rightarrow \\
\text { Formal Organizational Support } \rightarrow \\
\text { Research Innovation (Indirect) }\end{array}$ & 0.037 & 0.036 & 0.018 & 2.029 & 0.042 & 0.006 & 0.075 & \\
\hline $\begin{array}{l}\text { Consistent Knowledge Flows } \rightarrow \\
\text { Informal Organizational Support } \rightarrow \\
\text { Research Innovation (Indirect) }\end{array}$ & 0.066 & 0.063 & 0.028 & 2.321 & 0.020 & 0.015 & 0.124 & \\
\hline $\begin{array}{c}\text { Human Collective Intelligence } \rightarrow \\
\text { Formal Organizational Support }\end{array}$ & 0.288 & 0.291 & 0.084 & 3.425 & 0.001 & 0.126 & 0.456 & H3a supported \\
\hline $\begin{array}{l}\text { Human Collective Intelligence } \rightarrow \\
\text { Informal Organizational Support }\end{array}$ & 0.413 & 0.416 & 0.081 & 5.078 & 0.000 & 0.255 & 0.574 & H3b supported \\
\hline $\begin{array}{l}\text { Consistent Knowledge Flows } \rightarrow \\
\text { Formal Organizational Support }\end{array}$ & 0.236 & 0.237 & 0.091 & 2.594 & 0.010 & 0.053 & 0.408 & H4a supported \\
\hline $\begin{array}{l}\text { Consistent Knowledge Flows } \rightarrow \\
\text { Informal Organizational Support }\end{array}$ & 0.363 & 0.361 & 0.084 & 4.352 & 0.000 & 0.192 & 0.523 & H4b supported \\
\hline $\begin{array}{c}\text { Formal Organizational Support } \rightarrow \\
\text { Research Innovation }\end{array}$ & 0.157 & 0.155 & 0.050 & 3.131 & 0.002 & 0.059 & 0.253 & H5a supported \\
\hline $\begin{array}{c}\text { Informal Organizational Support } \rightarrow \\
\text { Research Innovation }\end{array}$ & 0.181 & 0.180 & 0.075 & 2.417 & 0.02 & 0.039 & 0.334 & H5b supported \\
\hline
\end{tabular}

Abbreviations in the table: $\beta$ (Beta coefficient), M (Mean), Stdev (Standard Deviation), T (T-test statistics), $\mathrm{P}(p$ value), $\mathrm{CI}$ (Confidence Intervals).

In support of H1, statistics reported in Table 5 highlighted the positive direct effect of Human Collective Intelligence on Research Innovation $(\beta=0.347 ; \mathrm{t}=4.853 ; p<0.001)$ and the positive indirect effects via Formal Organizational Support (Human Collective Intelligence $\rightarrow$ Formal Organizational Support $\rightarrow$ Research Innovation: $\beta=0.045 ; \mathrm{t}=2.196$; significant at $p=0.028$ ), respectively via Informal Organizational Support (Human Collective Intelligence $\rightarrow$ Informal Organizational Support $\rightarrow$ Research Innovation: $\beta=0.075$; $\mathrm{t}=1.896$; marginally significant at $p=0.058$ ), whereas the relationships Human Collective Intelligence $\rightarrow$ Formal Organizational Support $(\beta=0.288 ; \mathrm{t}=3.425 ; p=0.001 ; \mathrm{H} 3 \mathrm{a}$ thus being accepted) and Human Collective Intelligence $\rightarrow$ Informal Organizational Support ( $\beta=0.413 ; \mathrm{t}=5.078 ; p<0.001 ; \mathrm{H} 3 \mathrm{~b}$ thus being accepted), are positive and significant.

In support of $\mathrm{H} 2$, there can be observed the positive direct effect of Consistent Knowledge Flows on Research Innovation ( $\beta=0.353 ; \mathrm{t}=5.030 ; p<0.001$ ) and the positive indirect effects via Formal Organizational Support (Consistent Knowledge Flows $\rightarrow$ Formal Organizational Support $\rightarrow$ Research Innovation: $\beta=0.037 ; \mathrm{t}=2.029$; significant at $p=0.042$ ), respectively via Informal Organizational Support (Consistent Knowledge Flows $\rightarrow$ Informal Organizational Support $\rightarrow$ Research Innovation: $\beta=0.066 ; \mathrm{t}=2.321$; significant at $p=0.02)$. The relationship between Consistent Knowledge Flows and Formal Organizational Support $(\beta=0.236 ; \mathrm{t}=2.594 ; p=0.01 ; \mathrm{H} 4 \mathrm{a}$ is thus validated $)$, respectively the relationship between Consistent Knowledge Flows and Informal Organizational Support $(\beta=0.363 ; \mathrm{t}=4.352 ; p<0.001 ; \mathrm{H} 4 \mathrm{~b}$ is thus validated), are both positive and significant.

\section{Discussion and Conclusions}

\subsection{Summary and Discussion of Findings}

The testing of the inferred relationships brought to the fore that all the hypotheses were confirmed in the case of the present research sample and framework.

In this respect, the findings showed that, as knowledge brokers, online academic networks are systems aimed to support the access to human collective intelligence which exerts a positive influence on research innovation, both directly and indirectly by means of formal and informal 
organizational support. As facilitators of new social aggregations of individuals with specialized knowledge, competence, expertise and experience, online academic networks have become an agora for academics and researchers worldwide and an outlet for their works and projects. As proven within the scope of the present study, online academic networks succeed in their role of knowledge brokers as different forms of acumen and literacy are efficiently transferred from where they are known and developed to where they engender innovative opportunities, giving thus credit to Kislov, Wilson and Boaden's [19] and Malinovskyte, Mothe and Rüling's [21] approaches on knowledge brokerage and to Vătămănescu et al.'s [5] research on the network-based intellectual capital.

Acknowledging the transactional and social change frameworks of knowledge brokerage, as well, the paper has revealed the role of online academic networks in being systems which actively construct communication flows between knowledge creators and users, hence enhancing knowledge productive of capacity building. The results are consistent with previous evidence brought about by various studies $[18,21,26,30]$ when referring to creating bonds and bridging structural holes. Here, the findings underscore the positive and significant influences of the consistent knowledge flows among academics on research innovation in European emerging countries.

The validation of the hypotheses indicated that the linkages among peers happen both spontaneous, as direct and self-directed endeavours and by means of organizational support, be it formal and informal. Focusing on the latter, fragmented environments are also encouraged to be linked via institutional policies and practices, thus supporting prior insights $[59,61,62,64,65]$. Nevertheless, as the results indicated, the individual-level undertakings have a higher influence on the innovative outcomes. A possible explanation in this regard could be the fact that, in the case of the current research sample, the organizational support is not always explicit and consistent as to substantially determine academics to resort to online academic networks as knowledge wells.

\subsection{Research Originality and Implications}

The study adds to the extant literature in several main ways.

Firstly, it places the issue of knowledge brokerage within the framework of the academia field, given the scarcity of previous argumentative endeavours on the topic. As mentioned in the theoretical section, most of the studies approaching knowledge brokers and brokerage were dedicated to the for-profit sector, with a slight transition to the public domain over the past years. At this level, the research can be deemed as a useful piece conducive to an overall picture of the non-profit sector in terms of knowledge acquisition, diffusion, conversion and sharing.

Secondly, its scope exceeds the boundaries of an organization-centric perspective, giving credit to topical social, cultural and institutional phenomena in terms of deterritorialization. Focusing on online academic networks as knowledge brokers, the study brings forward the translocation of collaborative relationships, of knowledge associations and flows. Knowledge brokerage is thus extrapolated to transnational and trans-organizational levels, supporting the opportunity of bridging fragmented environments and, implicitly, structural holes beyond institutional borders and formal policies. As the findings themselves posited, spontaneous and individual-driven initiatives proved to be more powerful than mandatory norms in triggering and achieving research innovation. Nevertheless, by including organizational support as a mediating variable in the analysis, the paper provided a fresh insight and responded to the research gap signalled by different investigations $[5,18,59]$.

Thirdly, taking the aforementioned insight further, the study emphasizes the importance and relevance of capitalizing human collective intelligence and consistent knowledge flows by academics from emerging countries. Either placed in developed or in emerging countries, the higher education systems are subject to an ongoing process of innovation, especially in the vein of the network society and of the knowledge-based economy. Here, the intensive usage of the information and communication technology for sharing knowledge among the members of online academic networks (be they individuals or organizations) is liable to provide fruitful grounds for capacity building. 
Nowadays, the imperative for competitiveness is no longer a keystone of the for-profit sector, it has strongly immersed into the logic and existence of all kinds of organizations. Universities, research centres and institutes are funded (financially rewarded by the state and other stakeholders) based on their multifold performance, research innovation arising as a key criterion in many classifications. This is one of the main reasons why the access to the acumen of well-reputed scholars from top-ranked higher education institutions emerges as a key success factor for the less resourceful institutions. Subsequently, this reality should actually determine the management of universities to purposefully act towards establishing explicit institutional policies and practices for knowledge capitalization, towards cementing a collaborative organizational culture.

\subsection{Research Limits and Future Avenues}

As any other study, the current one has several limitations and would benefit from further improvements.

On the one hand, the convenience research sample is rather small and only comprises subjects from European emerging countries. The provided perspective is therefore context-specific and mainly unidirectional as the inferred relationships focus on the knowledge flows from well-known academics and institutions to the less resourceful counterparts and on the inherent innovative research outcomes. In this point, future studies may test the hypotheses in larger frames of reference and with higher samples.

On the other hand, the research addressed the frameworks of knowledge brokerage (i.e., knowledge system, transactional and social change frameworks) as an aggregate in the context of online academic networks. At this level, future studies may harness and leverage a more in-depth perspective on one of the three frameworks.

Finally, the research method and technique employed in the current study and, implicitly, the overall analysis would benefit from complementary investigations based on a different methodological design. For example, the usage of social network analysis would enrich the argumentative substance of the dedicated endeavours to knowledge brokerage.

Acknowledgments: The paper publication was supported by MDPI by means of the prize for the winner of the best presentation award at BSLab 2018 (Business Systems Laboratory 5th International Symposium "Cocreating Responsible Futures in The Digital Age"), held in Naples, 22-24 January 2018.

Author Contributions: G.D. and P.G. conceived the conceptual framework of the paper. G.D. and E.-M.V. developed the literature review and P.G. contributed to the introduction. A.G.A. was in charge of the statistical analysis and methods. E.-M.V. and G.D. discussed the findings and the implications of the research.

Conflicts of Interest: The authors declare no conflict of interest.

\section{References}

1. Tomlinson, J. Globalization and Culture; University of Chicago Press: Chicago, IL, USA, 1999.

2. Tomlinson, J. Deterritorialization; Wiley-Blackwell: Hoboken, NJ, USA, 2012.

3. OECD. New Sources of Growth: Knowledge-Based Capital. Key Analyses and Policy Conclusions. Synthesis Report. 2013. Available online: www.oecd.org/sti/inno/knowledge-based-capitalsynthesis.pdf (accessed on 12 November 2017).

4. Vătămănescu, E.M.; Andrei, A.G.; Leovaridis, C.; Dumitriu, L.D. Exploring network-based intellectual capital as a competitive advantage. An insight into European universities from developing economies. In Proceedings of the 7th European Conference on Intellectual Capital, Cartagena, Spain, 9-10 April 2015; Cegarra Navarro, J.G., Ed.; Academic Conferences and Publishing International Limited: Reading, UK, 2015; pp. 350-358.

5. Vătămănescu, E.M.; Andrei, A.G.; Dumitriu, L.D.; Leovaridis, C. Harnessing network-based intellectual capital in online academic networks. From the organizational policies and practices towards competitiveness. J. Knowl. Manag. 2016, 20, 594-619. [CrossRef] 
6. Ordóñez de Pablos, P. Measuring and Reporting Knowledge-Based Resources: The Intellectual Capital Report; Facultad de Ciencias Economicas, University of Oviedo: Oviedo, Spain, 2013.

7. Vătămănescu, E.M.; Gorgos, E.-A.; Andrei, A.-G.; Alexandru, V.-A. The Technological Advent and Dynamics of the Network Society. The "Middle-Aged Approach". Broad Res. Artif. Intell. Neurosci. 2016, 7, 16-30.

8. Andrei, A.G.; Zait, A.; Vătămănescu, E.M.; Pînzaru, F. Word of mouth generation and brand communication strategy: Findings from an experimental study explored with PLS-SEM. Ind. Manag. Data Syst. 2017, 117, 478-495. [CrossRef]

9. Vătămănescu, E.M.; Nistoreanu, B.G.; Mitan, A. Competition and Consumer Behavior in the Context of the Digital Economy. Amfiteatru Econ. 2017, 19, 354-366.

10. Vătămănescu, E.M.; Andrei, A.G.; Pînzaru, F. Investigating the online social network development through the Five Cs Model of Similarity: The Facebook case. Inf. Technol. People 2018, 31, 84-110. [CrossRef]

11. Di Fatta, D.; Cupido, F.; Dominici, G. The value of a network in the digital era: Insights about Doctor Chat case study. Int. J. of Elect. Mark. Retail. 2017, 8, 301-315. [CrossRef]

12. Di Fatta, D.; Caputo, F.; Evangelista, F.; Dominici, G. Small world theory and the World Wide Web: Linking small world properties and website centrality. Int. J. Mark. Bus. Syst. 2016, 2, 126-140. [CrossRef]

13. Bratianu, C.; Orzea, I. The entropic intellectual capital model. Knowl. Manag. Res. Pract. 2013, 11, $133-141$. [CrossRef]

14. Dabija, D.C.; Postelnicu, C.; Dinu, V.; Mihaila, A. Stakeholders' perception of sustainability orientation within a major Romanian University. Int. J. Sustain. Higher Educ. 2017, 18, 533-553. [CrossRef]

15. Bratianu, C.; Vătămănescu, E.-M. Students' perception on developing conceptual generic skills for business: A knowledge-based approach. VINE J. Inf. Knowl. Manag. Syst. 2017, 47, 490-505. [CrossRef]

16. Chan, A.; Chenhall, R.; Kohn, T.; Stevens, C. Interdisciplinary Collaboration and Brokerage in the Digital Humanities. Digit. Humanit. Q. 2017, 11, 1-10.

17. Belso-Martinez, J.A.; Diez-Vial, I.; Lopez-Sanchez, M.J.; Mateu-Garcia, R. The brokerage role of supporting organizations inside clusters: How does it work? Eur. Plan. Stud. 2018, 26, 706-725. [CrossRef]

18. Hammami, H.; Amara, N.; Landry, R. Organizational climate and its influence on brokers' knowledge transfer activities: A structural equation modelling. Int. J. Inf. Manag. 2013, 33, 105-111. [CrossRef]

19. Kislov, R.; Wilson, P.; Boaden, R. The 'dark side' of knowledge brokering. J. Health Serv. Res. Policy 2017, 22, 107-112. [CrossRef] [PubMed]

20. Aquilani, B.; Abbate, T.; Dominici, G. Choosing Open Innovation Intermediaries through their web-based platforms. Int. J. Digit. Account. Res. 2016, 16, 35-60. [CrossRef]

21. Malinovskyte, M.; Rüling, C.C.; Mothe, C. Knowledge brokerage: Towards an integrative conceptual framework. Presented at the XXIIIème Conférence de l'AIMS, Rennes, France, 26-28 May 2014. Available online: http:/ / www.strategie-aims.com/events/conferences/24-xxiiieme-conference-de-l-aims / communications/3166-knowledge-brokerage-towards-an-integrative-conceptual-framework/download (accessed on 6 February 2018).

22. Hargadon, A.B. Firms as knowledge brokers: Lessons in pursuing continuous innovation. Calif. Manag. Rev. 1998, 40, 209-227. [CrossRef]

23. Kidwell, D.K. Principal investigators as knowledge brokers: A multiple case study of the creative actions of PIs in entrepreneurial science. Technol. Forecast. Soc. Chang. 2013, 80, 212-220. [CrossRef]

24. Pawlowski, S.; Robey, D. Bridging user organizations: Knowledge brokering and the work of information technology professionals. Manag. Inf. Syst. Q. 2004, 28, 645-672. [CrossRef]

25. Ward, V.; House, A.; Hamer, S. Knowledge Brokering: The missing link in the evidence to action chain? Evid. Policy 2009, 5, 267-279. [CrossRef] [PubMed]

26. Kleinbaum, A.M. Organizational Misfits and the Origins of Brokerage in Intrafirm Networks. Admin. Sci. Q. 2012, 57, 407-452. [CrossRef]

27. Brass, D.J.; Galaskiewicz, J.; Greve, H.R.; Tsai, W. Taking stock of networks and organizations: A multilevel perspective. Acad. Manag. J. 2004, 47, 795-817. [CrossRef]

28. Burt, R.S. Structural Holes; Harvard University Press: Cambridge, UK, 1992.

29. Burt, R.S. Structural Holes and Good Ideas. Am. J. Sociol. 2004, 110, 349-399. [CrossRef]

30. Hahl, O.; Kacperczyk, A.; Davis, J.P. Knowledge Asymmetry and Brokerage: Linking Network Perception to Position in Structural Holes. Strateg. Org. 2016, 14, 118-143. [CrossRef] 
31. Hargadon, A.B. Brokering knowledge: Linking learning and innovation. Res. Org. Behav. 2002, $24,41-85$. [CrossRef]

32. Friedland, R.; Alford, R.R. Bringing Society Back in: Symbols, Practices and Institutional Contradictions; University of Chicago Press: Chicago, IL, USA, 1991.

33. Ordóñez de Pablos, P. Preface to the special issue: Emerging information technologies for effective knowledge management-towards high-performance business organizations and value networks. Hum. Fact. Ergon. Manuf. Serv. Ind. 2010, 20, 99-102. [CrossRef]

34. Gokmen, D. A qualitative research regarding the university administrators' capacity to use of management information tools. Procedia Soc. Behav. Sci. 2009, 1, 2480-2490. [CrossRef]

35. Leung, N.K.Y.; Lau, S.K.; Tsang, N. An ontology-based collaborative inter-organisational knowledge management network (CIK-NET). J. Inf. Knowl. Manag. 2013, 12, 1350005. [CrossRef]

36. Rathi, D.; Given, L.M.; Forcier, E. Interorganisational partnerships and knowledge sharing: The perspective of non-profit organisations (NPOs). J. Knowl. Manag. 2014, 18, 867-885. [CrossRef]

37. Laszlo, A. Leadership and Systemic Innovation: The case for Evolutionary Leadership. In Proceedings of the Keynote Speech Delivered at 5th Business Systems Laboratory International Symposium “Cocreating Responsible Futures in the Digital Age", Naples, Italy, 22-24 January 2018.

38. Malone, T.W. The Future of Work: How the New Order of Business Will Shape Your Organization. Your Management Style and Your Life; Harvard Business School Press: Boston, MA, USA, 2004.

39. Laszlo, A. Connecting the DOTS: The Design of Thrivable Systems through the Power of Collective Intelligence. Syst. Res. Behav. Sci. 2014, 31, 586-594. [CrossRef]

40. Wuchty, S.; Jones, B.F.; Uzzi, B. The Increasing Dominance of Teams in Production of Knowledge. Science 2009, 316, 1036-1039. [CrossRef] [PubMed]

41. Williams Woolley, A.; Chabris, C.F.; Pentland, A.; Hashmi, N.; Malone, T.W. Evidence for a Collective Intelligence Factor in the Performance of Human Groups. Science 2010, 330, 686-688. [CrossRef] [PubMed]

42. Soto-Acosta, P.; Colomo-Palacios, R.; Popa, S. Web knowledge sharing and its effect on innovation: An empirical investigation in SMEs. Knowl. Manag. Res. Pract. 2014, 12, 103-113. [CrossRef]

43. Kok, A. Intellectual capital management as part of knowledge management initiatives at institutions of higher learning. Electron. J. Knowl. Manag. 2007, 5, 181-192.

44. Sánchez, P.; Elena, S.; Castrillo, R. Intellectual capital dynamics in universities: A reporting model. J. Intellect. Cap. 2009, 10, 307-324. [CrossRef]

45. Wu, H.Y.; Chen, J.K.; Chen, I.S. Ways to promote valuable innovation: Intellectual capital assessment for higher education system. Qual. Quant. 2012, 46, 1377-1391. [CrossRef]

46. Ramírez, Y.; Gordillo, S. Recognition and measurement of intellectual capital in Spanish universities. J. Intellect. Cap. 2014, 15, 173-188. [CrossRef]

47. Veltri, S.; Silvestri, A. The Free State University integrated reporting: A critical consideration. J. Intellect. Cap. 2015, 16, 443-462. [CrossRef]

48. Ramírez Córcoles, Y.; Santos Peñalver, J.F.; Tejada Ponce, A. Intellectual capital in Spanish public universities: Stakeholders' information needs. J. Intellect. Cap. 2011, 12, 356-376. [CrossRef]

49. Bratianu, C.; Bolisani, E. Knowledge strategy: An integrated approach for managing uncertainty. In Proceedings of the 16th European Conference on Knowledge Management, Udine, Italy, 3-4 September 2015; Massaro, M., Garlatti, A., Eds.; Academic Conferences Publishing International Limited: Reading, UK, 2015; pp. 169-177.

50. Bratianu, C. The frontier of linearity in the intellectual capital metaphor. In Proceedings of the European Conference on Intellectual Capital, Haarlem, The Netherlands, 28-29 April 2009; Stam, C., Andriessen, D., Eds.; Academic Conferences Publishing International Limited: Reading, UK, 2009; pp. 97-103.

51. Nowicka, M.; Dima, I.C.; Stefan, C. Integrating the IC concept into strategies for the development of regional network systems. Eur. J. Bus. Soc. Sci. 2014, 1, 21-33.

52. Fernando, I. Community creation by means of a social media paradigm. Learn. Org. 2010, 17, 500-514. [CrossRef]

53. Kruse, P.; Geißler, P. Benefiting from external knowledge in open innovation processes. Int. J. Knowl. Syst. Sci. 2014, 3, 16-27. [CrossRef] 
54. Owen-Smith, J.; Powell, W.W. Knowledge networks as channels and conduits: The effects of spillovers in the Boston biotechnology community. Org. Sci. 2004, 15, 5-21. [CrossRef]

55. Dinu, V. The Knowledge-Based Economy: Implications for Higher Education in Economics and Business. Amfiteatru Econ. 2011, 13, 343-344.

56. Shu, C.; Page, A.L.; Gao, S.; Jiang, X. Managerial ties and firm innovation: Is knowledge creation a missing link? J. Prod. Innov. Manag. 2012, 29, 125-143. [CrossRef]

57. Valkokari, K.; Paasi, J.; Rantala, T. Managing knowledge within networked innovation. Knowl. Manag. Res. Pract. 2012, 10, 27-40. [CrossRef]

58. Ferguson, J.; Taminiau, Y. Conflict and learning in inter-organizational online communities: Negotiating knowledge claims. J. Knowl. Manag. 2014, 18, 886-904. [CrossRef]

59. Leon, R.D.; Vătămănescu, E.M. Storytelling as a knowledge strategy in higher education institutions. In Proceedings of the 16th European Conference on Knowledge Management, Udine, Italy, 3-4 September 2015; Garlatti, A., Massaro, M., Eds.; Academic Conferences and Publishing International Limited: Reading, UK, 2015; pp. 458-467.

60. Perez, J.R.; Ordóñez de Pablos, P. Knowledge management and organizational competitiveness: A framework for human capital analysis. J. Knowl. Manag. 2003, 7, 82-91. [CrossRef]

61. Nazari, J.A.; Herremans, I.M.; Isaac, R.G.; Manassian, A.; Kline, T.J.B. Organizational culture, climate and IC: An interaction analysis. J. Intellect. Cap. 2011, 12, 224-248. [CrossRef]

62. Gunsel, A.; Siachou, E.; Acar, A.Z. Knowledge management and learning capability to enhance organizational innovativeness. Procedia Soc. Behav. Sci. 2011, 24, 880-888. [CrossRef]

63. Kianto, A.; Andreeva, T.; Pavlov, Y. The impact of intellectual capital management on company competitiveness and financial performance. Knowl. Manag. Res. Pract. 2013, 11, 112-122. [CrossRef]

64. Tzortzaki, A.M.; Mihiotis, A. A review of knowledge management theory and future directions. Knowl. Process Manag. 2014, 21, 29-41. [CrossRef]

65. Tseng, K.A.; Lin, V.I.; Yen, S.W. Contingencies of intellectual capitals and financial capital on value creation. J. Intellect. Cap. 2015, 16, 156-173. [CrossRef]

66. Henseler, J.; Hubona, G.; Ray, P.A. Using PLS path modeling in new technology research: Updated guidelines. Ind. Manag. Data Syst. 2016, 116, 2-20. [CrossRef]

67. Hair, J.F.; Hult, G.T.M.; Ringle, C.M.; Sarstedt, M. A Primer on Partial Least Squares Structural Equation Modeling (PLS-SEM), 2nd ed.; Sage: Thousand Oaks, CA, USA, 2017.

68. Ringle, C.M.; Wende, S.; Becker, J.-M.; SmartPLS 3. Boenningstedt: SmartPLS GmbH. 2015. Available online: http:/ / www.smartpls.com (accessed on 3 March 2018).

69. Hu, L.T.; Bentler, P.M. Cutoff criteria for fit indexes in covariance structure analysis: Conventional criteria versus new alternatives. Struct. Equ. Model. Multidiscip. J. 1999, 6, 1-55. [CrossRef]

70. Fornell, C.; Larcker, D.F. Evaluating structural equation models with unobservable variables and measurement error. J. Market. Res. 1981, 18, 39-50. [CrossRef]

71. Chin, W.W. How to write up and report PLS analyses. In Handbook of Partial Least Squares: Concepts, Methods and Applications in Marketing and Related Fields; Esposito Vinzi, V., Chin, W.W., Henseler, J., Wang, H., Eds.; Springer: Berlin, Germany, 2010; pp. 655-690.

72. Henseler, J.; Ringle, C.M.; Sarstedt, M. A new criterion for assessing discriminant validity in variance-based structural equation modeling. J. Acad. Market. Sci. 2015, 43, 115-135. [CrossRef]

73. Diamantopoulos, A.; Siguaw, J.A. Formative versus Reflective Indicators in Organizational Measure Development: A Comparison and Empirical Illustration. Br. J. Manag. 2006, 17, 263-282. [CrossRef]

74. Hair, J.F.; Hult, G.T.M.; Ringle, C.M.; Sarstedt, M. A Primer on Partial Least Squares Structural Equation Modeling (PLS-SEM); Sage: Los Angeles, CA, USA, 2014.

(C) 2018 by the authors. Licensee MDPI, Basel, Switzerland. This article is an open access article distributed under the terms and conditions of the Creative Commons Attribution (CC BY) license (http://creativecommons.org/licenses/by/4.0/). 